\title{
HOUSEHOLD PESTICIDES AND THEIR PRACTICES IN DHAKA CITY
}

\author{
Afroza Sultana*, Magfur Raheman and Mosharraf Hossain \\ Department of Zoology, Jagannath University, Dhaka, Bangladesh
}

Structured questionnaires were used for formal and informal interviews to determine the use of household pesticides among 120 residents of Dhaka city. Poison chalks were the most preferred method for the pest control (68\%), followed by mosquito coil (63\%), ant-killer powder (24\%) and aerosol (10\%). Mosquitoes were the most prevalent pests (100\%), followed by cockroaches $(96 \%)$ and flies (87\%). The most common non-chemical methods of pest management were mosquito bed nets (58\%). Only (28\%) of the respondents read manufacturer's instructions for use. The disposal techniques were very risky, $(67 \%)$ of the respondents threw it away and (25\%) disposed in correct place. Kitchen was the most common place to use household pesticides. The frequency of pesticides used were varied, Mosquito coils were used every day and poison chalk once a week. Pesticides application was inappropriately done in many households mainly due to inadequate knowledge about use.

As in many developing countries, Bangladesh lacks sufficient information on pesticide use, even at the regional level. The home environment is widely considered to be the most common pesticide-treated indoor environment, where the residents themselves apply the pesticides (WHO 1997). Pesticide use contributes to indoor contamination and has the potential to cause human poisoning that are major environmental and health challenges (Butte et al. 2002, Bouwman et al. 2009). Furthermore, exposure to household pesticides is dependent on the amount and place of use, usage practices, storage and disposal methods (Grossmann 1995, Grey et al. 2006). In developing countries there is often a lack of opportunities for careful management, storage and disposal that reduces hazards and risks of pesticides and pesticide handling (Kondrasen et al. 2003).

Of the 120 respondents, 64 were men (53\%), 110 were adult (92\%). Among the respondents $(74 \%)$ were married, $(13 \%)$ were illiterate and $(45 \%)$ were low educational status.

\footnotetext{
*Author for correspondence: E. mail: afrozasultana82@gmail.com
} 
Table 1. Practices of different parameters against four commonly used household pesticides in Dhaka city

\begin{tabular}{|c|c|c|c|c|}
\hline Parameters & $\begin{array}{c}\begin{array}{c}\text { Poison } \\
\text { chalk }\end{array} \\
(\mathrm{N}=82) \\
(\%)\end{array}$ & $\begin{array}{l}\text { Mosquito } \\
\text { coil } \\
\qquad(\mathrm{N}=76) \\
(\%)\end{array}$ & $\begin{array}{c}\text { Ant killer } \\
\text { powder } \\
(\mathrm{N}=29) \\
(\%)\end{array}$ & $\begin{array}{c}\text { Aerosol } \\
(\mathrm{N}=12) \\
(\%)\end{array}$ \\
\hline \multicolumn{5}{|l|}{ Frequency of use } \\
\hline Everyday & 6 & 87 & 10 & 50 \\
\hline At least once per week & 61 & 7 & 34 & 25 \\
\hline At least once per month & 24 & 4 & 28 & 17 \\
\hline At least once a year & 79 & 3 & 28 & 8 \\
\hline \multicolumn{5}{|l|}{ Place of use } \\
\hline Kitchen & 87 & 4 & 83 & 17 \\
\hline Bedroom & - & 96 & 17 & 83 \\
\hline Bathroom & 13 & - & - & - \\
\hline \multicolumn{5}{|l|}{ Attitude to handle pesticides } \\
\hline Wash hands & 84 & 8 & 59 & 17 \\
\hline Do not wash & 16 & 92 & 41 & 83 \\
\hline \multicolumn{5}{|l|}{ Health perception } \\
\hline Agree & 12 & 53 & 69 & 75 \\
\hline Disagree & 1 & 11 & 24 & 17 \\
\hline Do not know & 87 & 37 & 7 & 8 \\
\hline
\end{tabular}

Mosquito coils and aerosols were used every day in 66 of 76 (87\%) and 6 of $12(50 \%)$ households respectively. Poison chalk and ant killer powder were used at least once per week in 50 of $82(61 \%)$ and 10 of $29(34 \%)$ households, respectively. Poison chalk and ant killer powder were used mostly in kitchen area of 71 of $82(86 \%)$ and 24 of $29(82 \%)$ households, respectively. Among the poison chalk users, $(84 \%)$ reported washing hands after touching the product and $(92 \%)$ mosquito coil users not washing hands. Among the users of various household pesticides, from $(87 \%)$ poison chalk users to $(37 \%)$ mosquito coil users did not know that the use of certain household pesticides could harm their health. Seventy five percent of the users of mosquito control aerosol spray, $(69 \%)$ of the ant killer powder users and $(53 \%)$ of the mosquito coil users agreed that these products were harmful to their health (Table 1).

Mosquitoes were the most prevalent pests reported $(100 \%)$, followed by cockroaches (96\%), flies (73\%) and ants (71\%). However, in households (68\%) respondents used poison chalk for cockroaches' control. Among the users, $(63 \%)$ used mosquito coil, (24\%) ant killer powder and the lower percentage $(10 \%)$ used 
aerosol for mosquito control. The major non-chemical methods of indoor pest control were bed nets (58\%).

Among the participants, $(67 \%)$ used to dispose the containers by just throwing away outside and (25\%) into the dustbins. Only $(11 \%)$ of the respondents had previous knowledge about pesticides label instructions before applying in their households. Those who had used the insecticide before $(61 \%)$ felt no need to read the instructions every time they purchased the product or to use. Among the respondents only (28\%) read the pesticides guideline published in the label.

Based on the results of the present experiment, it may be recommended that Public awareness program through mass media may reduce the risks of indoor application of pesticides and there should have safe storage facilities at properly ventilated place with proper labeling system on the pesticides containers.

\section{LITERATURE CITED}

BOUWMAN, H. and KYLIN, H. 2009 Malaria control insecticide residues in breast milk: the need to consider infant health risks. Environmental Health Perspectives. 117(10): 1477-1480.

BUTTE, W. and HEINZOW, B. 2002. Pollutants in house dust as indicators of indoor contamination. Reviews of Environmental Contamination and Toxicology. 175: 1-46.

GREY, C.N.B., NIEUWENHUIJSEN, M.J. and GOLDINGS, J. 2006 . Use and storage of domestic pesticides in the UK. Sci Total Environ. 368(2-3): 465-70.

GROSSMANN, J. 1995. What's hiding under the sink: dangers of household pesticides. Environ Health Perspect 103(6): 550-4.

KONDRASEN, F., VAN DER HOEK, W., COLE, D. C., HUTChinson, G., DAISlEy, H., SING, S. and EDDLESTON, M. 2003. Reducing Acute Poisoining in Developing Countries-Options for Restricting Availability of Pesticides, Toxicology 192 (23):249-261.

WORLD HEALTH ORGANIZATION. 1997. Technical Report number. WHO, Copenhagen, Denmark: WHO regional publications European; Assessment of exposure to indoor air pollutants. 